Богуслаев В. А., Жеманюк П. Д., Мозговой В. Ф., Балушок К. Б., Панасенко В. А.

АО «Мотор Сич». Украина, г. Запорожье

\title{
ПРОГРЕССИВНЫЕ МЕТОДЫ ОБРАБОТКИ ДЕТАЛЕЙ АВИАЦИОННЫХ ДВИГАТЕЛЕЙ ИЗ КОМПОЗИЦИОННЫХ МАТЕРИАЛОВ НА АО «МОТОР СИЧ»
}

\begin{abstract}
Представлены технологические новации, разработанные и внедрённые в производство на АО «Мотор Сич» для обработки изделий из полимерных композиционных материалов. Представлен краткий анализ проблем механической обработки полимерных композиционных материалов. Показаны производственные решения некоторых проблем механической обработки полимерных композиционных материалов, разработанные на АО «Мотор Сич». [dx.doi.org/10.29010/088.2]
\end{abstract}

Ключевые слова: механическая обработка; полимерные композищионные материаль; режущий инструмент; специальный инструмент; приспособления.

В современных турбореактивных двигателях все более широкое применение находят новые конструкционные материалы, обладающие высокими эксплуатационными свойствами. К ним относят композиционные материалы на полимерной основе, армированные стеклянными, углеродными, органическими волокнами и тканями. Например, применение современных полимерных композиционных материалов (ПКМ) при изготовлении конструктивных элементов вертолетов позволяет снизить массу агрегатов на $20 \%$ и уменьшить трудоёмкость изготовления на $30-50 \%$. При этом, снижаются затраты на производство и эксплуатацию. Такие композиты как волокнистый углепластик на $70 \%$ легче конструкционной стали и на $40 \%$ - алюминиевого сплава, но не уступают им по эксплуатационным показателям.

Наряду с высокими физико-механическими, химическими и антифрикционными свойствами полимерные композиционные материалы обладают способностью гасить вибрации и шумы. Снижение шума авиационной техники при эксплуатации является актуальной задачей. Снижение излучаемого двигателем шума с помощью звукопоглощающих конструкций и панелей открывает возможность расширения географию полётов самолётов в различные регионы.

Звукопоглощающие конструкции панелей, обрабатываемые на АО «Мотор Сич», представляют собой сэндвичевые оболочки сложной конфигурации. Оболочки состоят из двух термосклеенных между собой половинок. Они несут на себе большое количество мелкоразмерных отверстий диаметром 1,6-2,4 мм для поглощения шума. Звукопоглощающая панель имеет множество воздушных камер, препятствующих распространению звуковых волн. Мелкоразмерные отверстия, выполненные на финишных операциях обработки панелей, усиливают шумопоглощающий эффект.

К инструменту для механической обработки ПКМ предъявляются высокие и разнообразные требования. В процессе обработки этих материалов технологи сталкиваются с такими проблемами как расслоение материала, перегрев, образование заусенцев, абразивный износ режущего инструмента. Сверление отверстий диаметром до 3 мм связано с рядом трудностей, главной из которых считается поломка режущего инструмента. Кроме этого, обработка ПКМ осложняется рядом других проблем:

- высокая твердость наполнителя и его абразивное воздействие на режущий инструмент;

- ярко выраженная анизотропия свойств обрабатываемого материала;

- относительная сложность получения высокого качества поверхности из-за слоистой структуры материала;

- высокие упругие свойства композиционных материалов, что вызывает повышенный износ инструмента по задней поверхности;

- низкая теплопроводность композитов, что вызывает повышенный перегрев режущего инструмента и препятствует нормальному распределению теплового баланса при резании;

- возникающая деструкция полимерного связующего способствует адсорбционному износу инструмента;

- невозможность применения СОЖ для большинства полимерных материалов.

Балушок К. Б., Панасенко В. А., 2019 


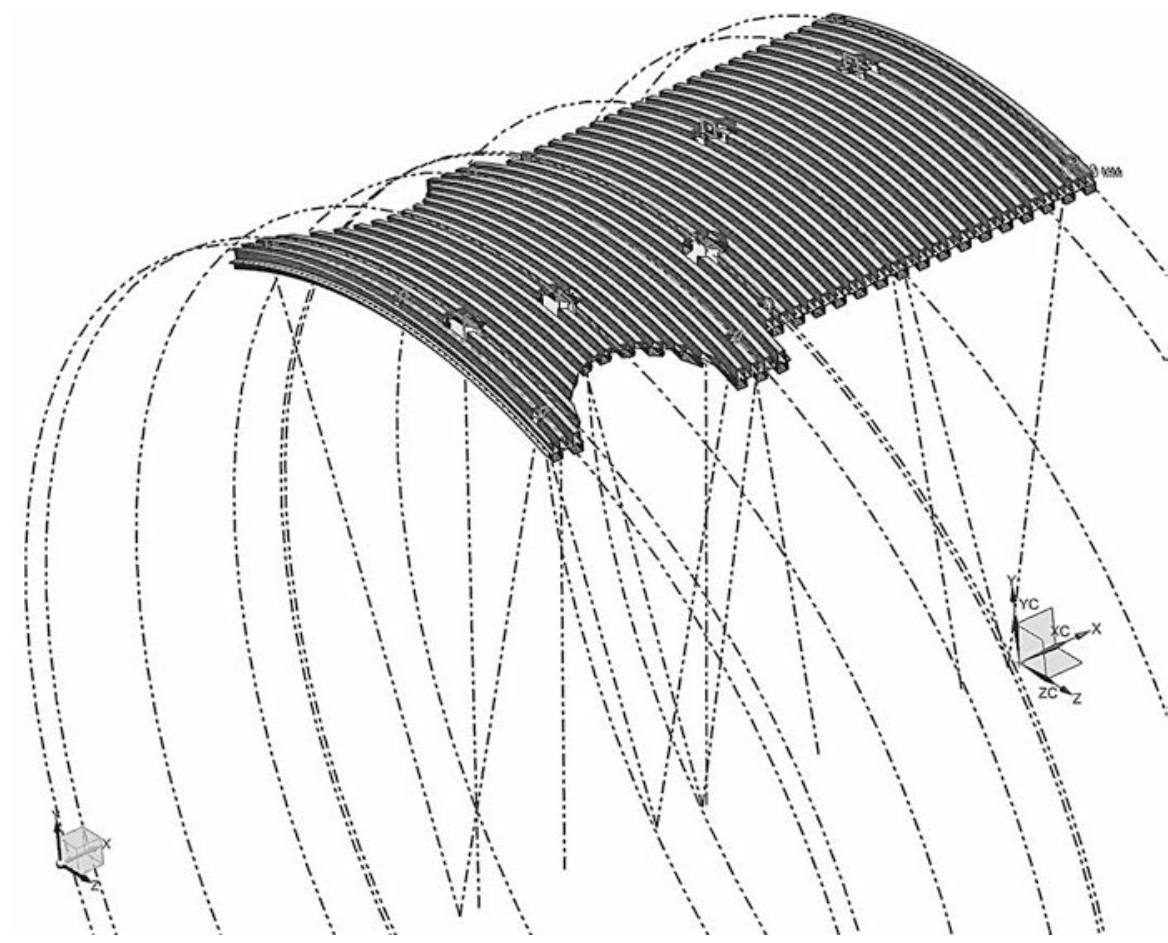

Рис. 1. Панель шумоглушения на корпусе двигателя

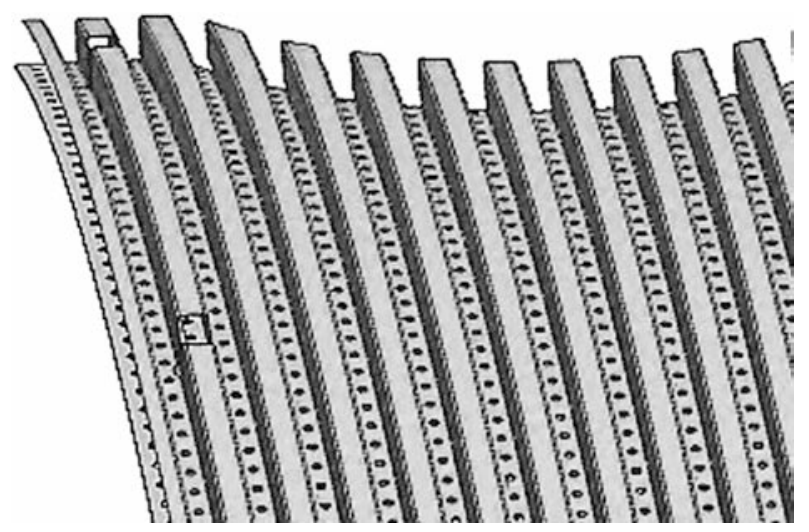

Рис. 2. Расположение отверстий в панели шумоглушения

В связи с этим, обработка деталей из ПКМ с заявленными конструкторскими требованиями и гарантированным качеством является актуальной задачей для современного авиационного производства.

Панели шумоглушения представляют собой оболочки, которые конструктивно охватывают корпус двигателя, создавая шумозащитный барьер. Панели, собранные и закрепленные по внешнему корпусу двигателя, охватывают зоны, отличающиеся повышенным шумом. Детали выполнены из стеклотекстолита, имеющего в своей основе мелкоячеистую стеклоткань, что позволяет при прессовании получать рельефные детали мелких размеров.

Конструктивно панели шумоглушения имеют прямую и обратную кривизну. Отверстия располагаются по нормали к криволинейной поверхности основания (как правило цилиндрической или кони- ческой формы) и выполнены с двух сторон деталей. Максимальное количество отверстий в панели с прямой кривизной составляет 2500 единиц.

Механическую обработку панелей шумоглушения на $\mathrm{AO}$ «Мотор Сич» выполняют на новейших высокоскоростных 5-ти координатных обрабатывающих центрах с ЧПУ КХ-200 (фирма HURON) и HPline plus (фирма Robot Sistems), оснащённые системой ЧПУ Sinumerik-840D. Станки имеет высокие технические характеристики. Шпиндельный узел оснащён высокоскоростным шпинделем, что позволяет обеспечить требуемые режимы резания. Кинематика станков за счёт специальной конструкции шпиндельной головки позволяет обрабатывать отверстий, расположенные по нормали к сложной поверхности шумоглушащих панелей. На станке также выполняется обработка контура детали концевыми фрезами.

Для сверления отверстий небольшие детали устанавливают на приспособление и сверху прижимают центрирующей плитой, имеющей координатную сетку отверстий, совпадающую с будущей координатной сеткой отверстий на деталях. Прижимная плита придаёт дополнительную жесткость детали и исключает деформирование заготовки во время обработки. Для панелей больших габаритов вместо плиты применялись обжимные резиновые ремни или поперечные планки крепления.

Ряд панелей конструктивно требуют сверления отверстий с двух сторон. Для этого панель после выполнения сверления с одной стороны переворачивали на другую сторону, устанавливали в дру- 


\section{3/2019 Технологические}
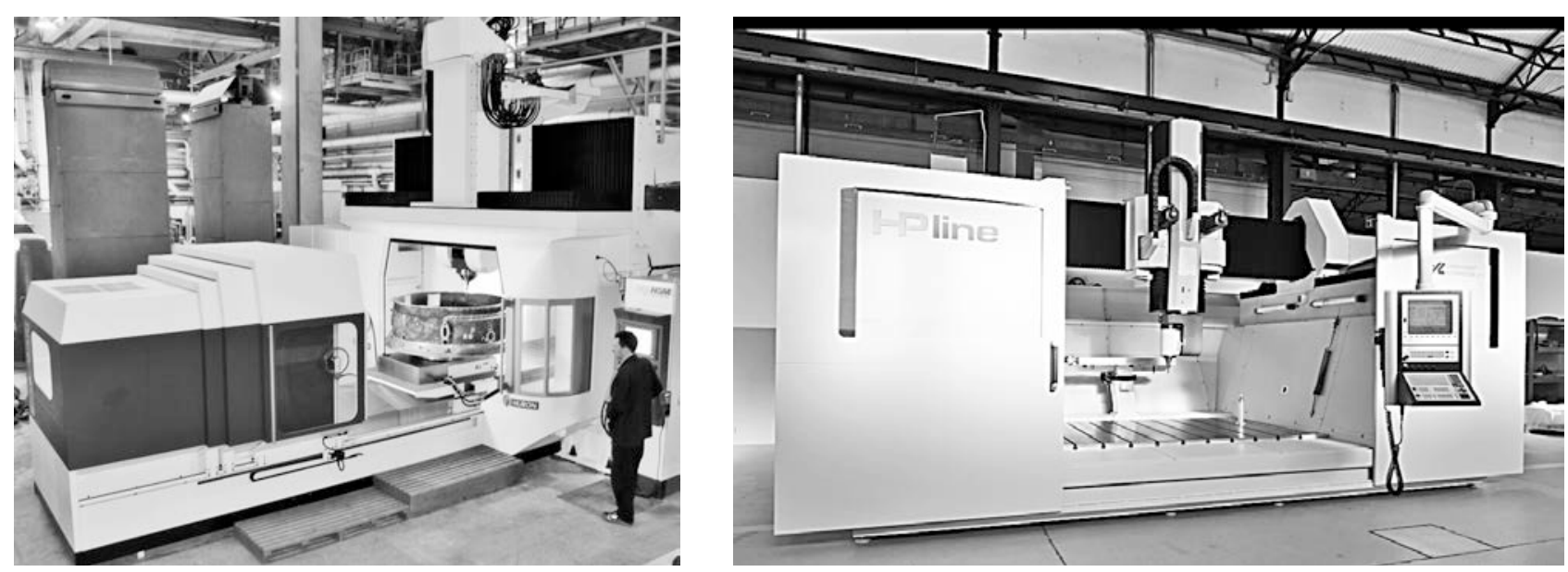

Рис. 3. 5-ти координатные обрабатывающие центра КХ-200 и НР-2616
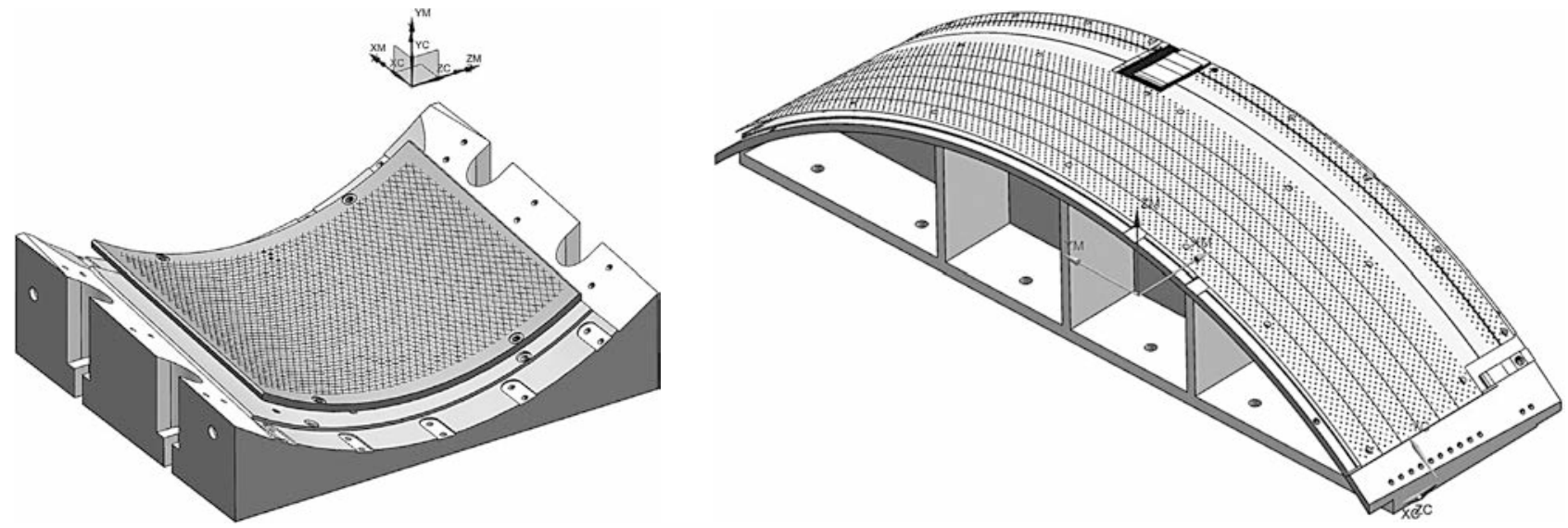

Рис. 4. Приспособления для крепления панели на станках

гое приспособление и операция сверления продолжалась

Как показал практический опыт, процесс сверления мелкоразмерных отверстий до 3 мм в деталях из ПКМ трудно поддается управлению. Обычный концевой инструмент из быстрорежущей стали и твердых сплавов быстро выходит из строя, и после обработки на поверхности детали остаются заусенцы или наволакивание материала. Новолакивание приходится удалять вручную.

Мелкоразмерный режущий инструмент из быстрорежущей стали для обработки ПКМ малопригоден в связи с преждевременным выкрашиванием режущих кромок и, как следствие - поломкой. Эта особенность связана с сильно развитой карбидной неравномерностью быстрорежущей стали. Другим немаловажным фактором является возможное технологическое пересечение инструмента со скрытыми ребрами жесткости детали. При пересечении рёбер во время рабочего хода происходит увод сверла, деформирование и, как правило, его поломка.

Часто происходит заклинивание сверла при обратном ходе от пружинения заготовки. В этом

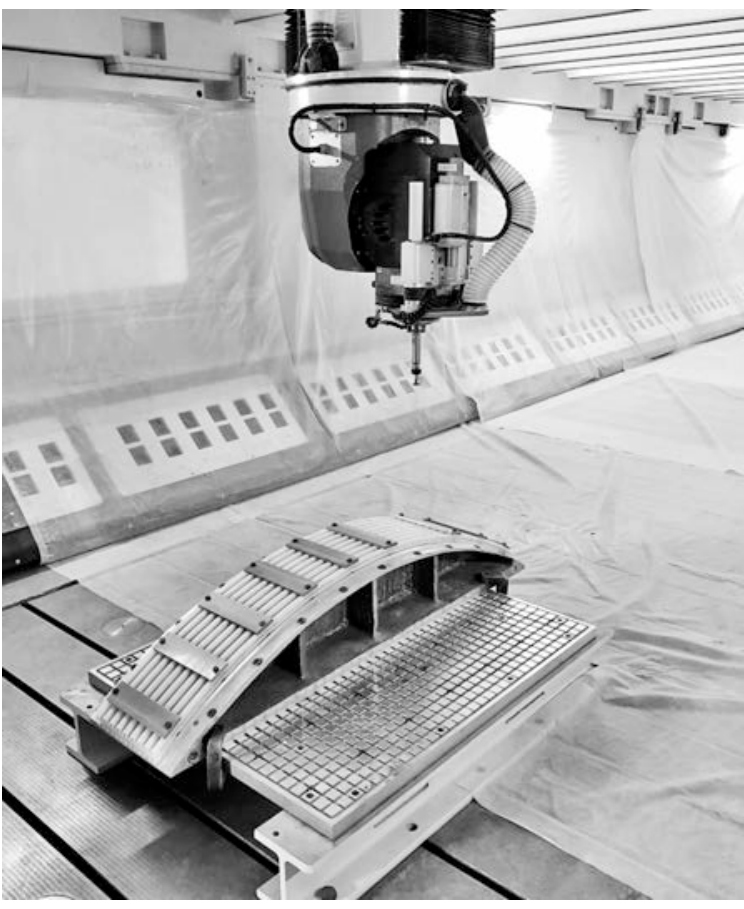

Рис. 5. Заготовка панели закреплённая на столе станка HPline plus перед обработкой 
случае, как правило, также происходит поломка инструмента.

Универсальные сверла для обработки металлов имеют слишком большой угол при вершине, что негативно сказывается на процессе сверления. Главные режущие кромки стандартного сверла «вытягивают» волокна материала и сверло не в состоянии срезать наволачивание.

В качестве режущего инструмента для обработки ПКМ известные мировые инструментальные фирмы предлагают большую номенклатуру цельнотвердосплавных сверл и фрез с мехкреплением. Так, компания Taegu Тес предлагает инструмент для обработки композитов. В нее вошли мелкоразмерные сверла с алмазным покрытием, фрезерные пластины из поликристаллического алмаза (PCD), концевые твердосплавные фрезы. Компания Hoffmann Group для обработки пластиков и композитных материалов предлагает специальные инструментальные материалы, обладающие высокой устойчивостью к абразивному износу - кубический нитрид бора (КНБ) и поликристаллические алмазы (PKD). Альтернативу им составляют твердосплавные инструменты с алмазным покрытием. Конструкция инструментов отличается наличием разнонаправленных зубьев - правой или левой спирали и специальной геометрии, препятствующей расслоению материала. Разнонаправленность спирали обеспечивает необходимое направление схода стружки при обработке.

Перечень фирм, предлагающих специальный инструмент не исчерпывается упомянутыми. Основным препятствием для применения предлагаемого инструмента в серийном или мелкосерийном производствах является его цена и невозможность полного восстановления режущих свойств инструмента после переточки.

Для обработки деталей из ПКМ на АО «Мотор Сич» был разработан комплекс мероприятий по оптимизации сверления мелкоразмерных отверстий в сэндвичевых панелях, включающий разработку конструкции специального сверла (роутера) и подбор оптимальных режимов резания на станке.

За критерий технологической стойкости инструмента была принята ширина фаски износа инструмента по задней поверхности зуба. Превышение износа свыше 0,35 мм ведет к ухудшению качества обработанной поверхности и росту мощности резания. Это было положено в основу собственной конструкции роутера диаметром 2,5 мм.
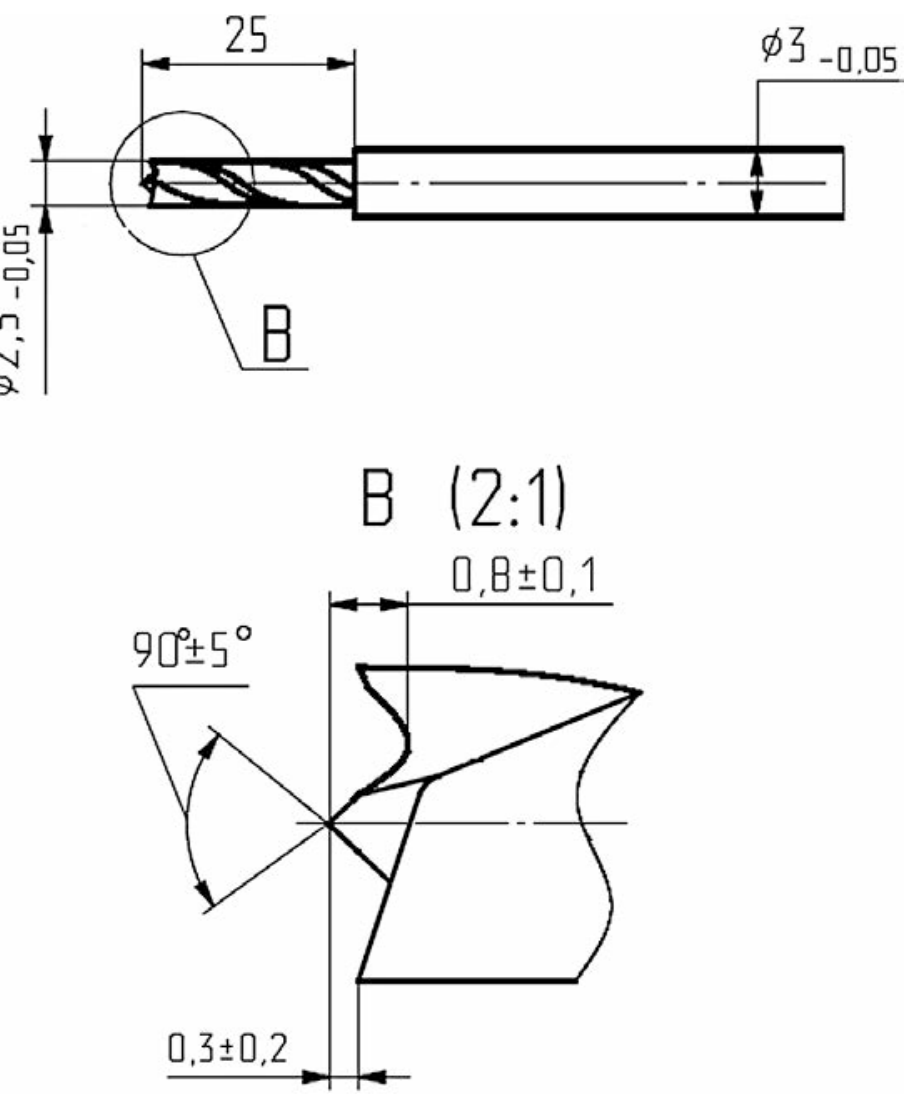

Рис. 6. Роутер диаметром 2,5 мм

Запроектированный роутер для сверления отверстий диаметром 2,5 мм был изготовлен из твердого сплава H10F (SANDVIK) и альтернативного сплава DK-460UF. Инструмент изготавливался на 5-ти координатном заточном станке с ЧПУ GEMINI. Допуск осевого биения режущих кромок относительно оси хвостовика составлял не более 0,01 мм. Допуск радиального биения по ленточке относительно оси хвостовика - не более 0,01 мм. Учитывая то, что сверло работает с большими оборотами, предварительно инструмент был динамически отбалансирован в инструментальной оснастке до 0,5 г·мм.

Особенностью конструкции роутера является угол при вершине $90^{\circ}$ и наличие по торцу инструмента режущих кромок, которые при вращении инструмента подрезают вытягивающиеся волокна стеклопластика. За счет этого удалось существенно уменьшить наволакивание материала при выходе инструмента из материала, что дало возможность значительно сократить долю ручного труда на слесарных операциях, а в некоторых случаях и вообще отказаться от них.

Режимы резания при обработке отверстий составили $-n=12000$ об/мин, $S$ м $=600$ мм/мин. Соответственно, скорость резания $-V=94$ м/мин. Внутренняя поверхность отверстий удовлетворяла конструкторским требованиям и удалось добиться 


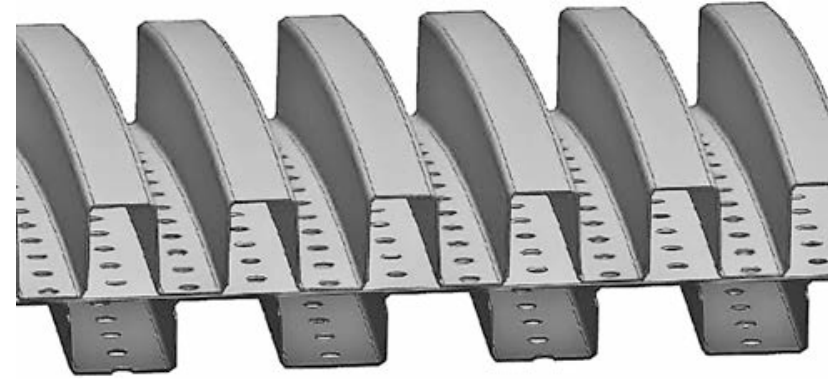

Рис. 7. Просверленные роутером отверстия в панели

практически полного отсутствия заусенцев и наволакивания материала.

Стойкость роутера составила около 120 мин. В процессе работы происходил естественный износ инструмента. Для восстановления режущих свойств инструмента проводилась переточка сверла. Принимая во внимание собственное изготовление роутера, восстановление режущих свойств достигала $100 \%$.

Для сверления в стеклопластиковой панели отверстий большого диаметра были запроектированы и изготовлены специальные чашечные зенкеры. Диаметр рабочей части инструмента соответствовал диаметру обрабатываемого отверстия в панели. Были изготовлены шесть градаций зенкеров на диаметры 12, 32.5, 34.5, 42.5, 46, 177.6 мм. Зенкер с рабочим диаметром 177,6 мм был изготовлен сборным. За один рабочий ход зенкера получалось одно отверстие в детали. В качестве отходов материала выхо-

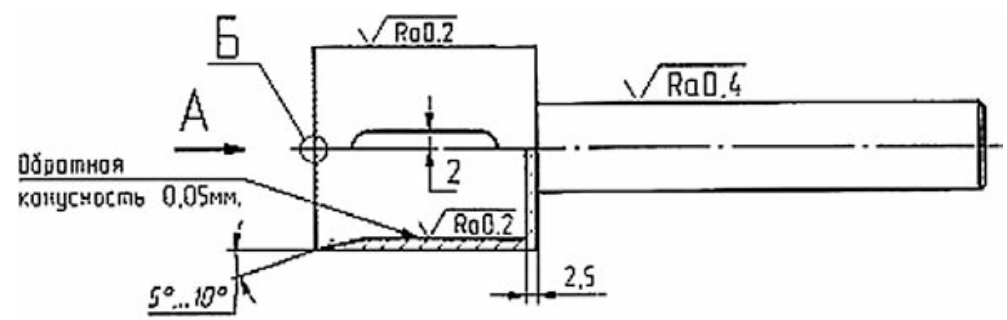

Б
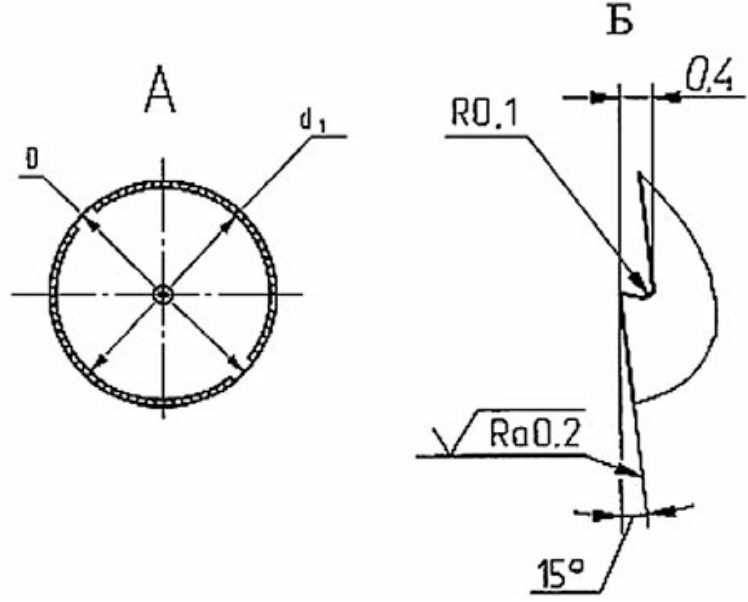

Рис. 8. Чашечный зенкер для обработки отверстий среднего и большого диаметра дил вырезанный круг стеклопластиковой панели. Инструмент был выполнен из быстрорежущей стали Р12МЗФЗК10-МП с последующей закалкой до 68...70 HRC. Допуск осевого биения режущих кромок относительно оси хвостовика составлял не более 0,02 мм. Допуск радиального биения относительно оси хвостовика - не более 0,01 мм.

Чашечный зенкер во время работы совершает вертикальные движения по оси «Z» станка так, что за один ход формировалось готовое отверстие. Режимы резания при обработке чашечным зенкером составили: $n=10000$ об/мин, $S_{\mathrm{M}}=800 \mathrm{мм} / \mathrm{мин.}$ Соответственно, средняя скорость резания составила $V=690$ м/мин. Конструкция зенкера позволяла производить переточку инструмента на заточных станках с полным восстановлением режущих свойств инструмента.

Одним из широко применяемых методов механической обработки композиционных материалов является фрезерование. Фрезерованием формируют внешний контур панелей для обеспечения их взаимной собираемости на двигателе, выполняют различного рода поднутрения и пазы. Из литературных источников известно, что при фрезеровании полимерных композиционных материалов рекомендуется работать фрезами из твердого сплава ВК8. При этом, инструмент должен отвечать следующим критериям:

- передний угол $-\gamma=20-25^{\circ}$, задний $-\alpha=10-12^{\circ}$;

- подача на зуб $-S z=0,15-0,17$ мм/зуб;

- глубина резания $-t=0,5-0,6$ мм.

Специалистами установлено, что неоправданное увеличение подачи $S z$ и глубины резания $t$ приводит к резкому снижению работоспособности режущего инструмента, даже оснащенного твердым сплавом ВК8. При неоправданном увеличении $S z$ и $t$ начинается интенсивное расслоение композиционного материала, разрушается связка, и волокна упрочнителя вырываются с поверхности под действие сил резания. Это ведёт к наволакиванию материала и ухудшению качества обработанной поверхности.

Инструментальные фирмы наряду с фрезами с режущими кромками из поликристаллических алмазов предлагают твердосплавные фрезы с алмазным покрытием. Скорости резания при этом рекомендуются в диапазоне от 150 до 350 м/мин, подача - от 0,06 до 0,1 мм/зуб. Особенностью предлагаемых фрез является специальная вогнутая форма режущей кромки, препятствующая расслоению материала.

Для решения задачи по подрезке торцев панелей шумоглушения и выполне- 


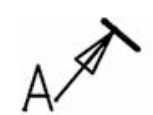

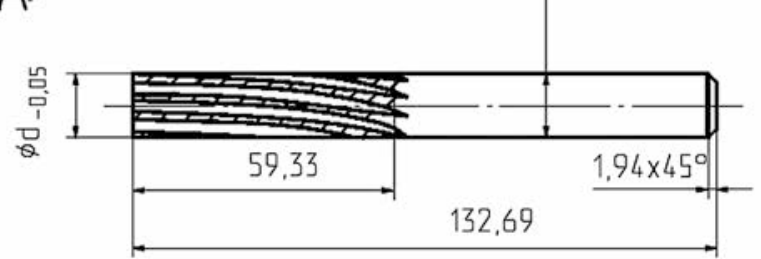

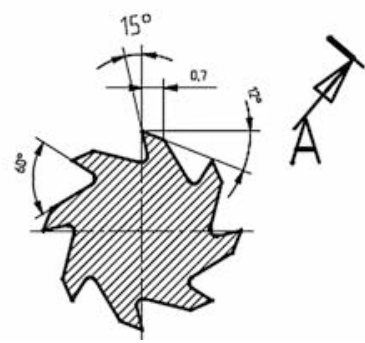

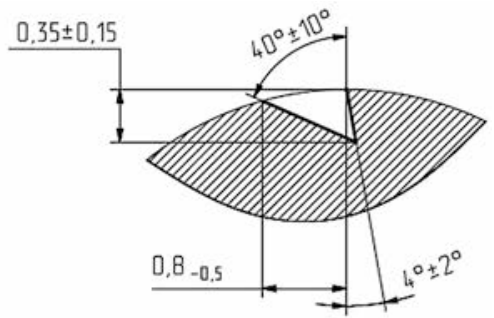

Рис. 9. Цельнотвердосплавная фреза для подрезки панелей шумоглушения

нию фрезерных переходов на АО «Мотор Сич» была запроектирована и изготовлена цельнотвердосплавная концевая фреза. Фреза изготовлена из сплава H10F и DK460UF.

Режимы резания при фрезеровании панелей составили $V$ рез $=175$ м/мин, $n=8000$ об/мин, $S_{\mathrm{M}}=1075 \mathrm{mм} / \mathrm{мин,} \mathrm{подача} \mathrm{при} \mathrm{врезании} \mathrm{составила}$ $S_{\mathrm{M}}=540 \mathrm{мм} /$ мин.

Испытания показали, что по сравнению с технически обоснованными режимами резания для фрез инструментальных фирм, заводские режимы резания находились в рекомендуемом диапазоне и отвечали требованиям по точности и шероховатости обрабатываемых поверхностей. Обработка проводилась без применения рабочей охлаждающей жидкости.

В процессе дальнейшей обработки деталей, выполненных из полимерных материалов, подтвердился правильно выбранный путь решения производственной задачи.

Boguslaev V. A., Zhemanjuk P. D., Mozgovoj V. F., Balushok K. B., Panasenko V. A.

Motor Sich, JSC. Ukraine, Zaporozhye

\section{PROGRESSIVE METHODS FOR PROCESSING AIRCRAFT ENGINE PARTS FROM COMPOSITE MATERIALS AT MOTOR SICH JSC}

Technological innovations developed and introduced into production at «Motor Sich», JSC for processing products from polymer composite materials are presented. A brief analysis of the problems of machining polymer composite materials is presented. Production solutions to some problems of the mechanical processing of polymer composite materials developed at «Motor Sich», JSC are shown. [dx.doi.org/10.29010/088.2]

Keywords: mechanical processing; polymer composite materials; cutting tool; special tool; fixtures. 